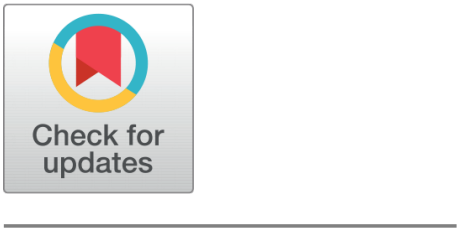

G OPEN ACCESS

Received: 02.01.2021

Accepted: 28.02.2021

Published: 12.04 .2021

Citation: Pandey SK, Tyagi HK (2021) A journey towards the commitments of national education policy 2020 through concept mapping. Indian Journal of Science and Technology 14(12): 984-989. htt ps://doi.org/10.17485/IJST/v14i12.5

* Corresponding author.

Tel: 7011944401

kumarsunulpandey@gmail.com

Funding: None

Competing Interests: None

Copyright: (c) 2021 Pandey \& Tyagi. This is an open access article distributed under the terms of the Creative Commons Attribution License, which permits unrestricted use, distribution, and reproduction in any medium, provided the original author and source are credited.

Published By Indian Society for Education and Environment (iSee)

ISSN

Print: 0974-6846

Electronic: 0974-5645

\section{A journey towards the commitments of national education policy 2020 through concept mapping}

\author{
Sunil Kumar Pandey ${ }^{1 *}$, Harish Kumar Tyagi ${ }^{2}$ \\ 1 Research Scholar, Amity Institute of Education, Amity University, Uttar Pradesh, \\ Tel.: 7011944401 \\ 2 Head, Amity Institute of Behavioural and Allied Science, Amity University, Uttar Pradesh
}

\section{Abstract}

Objectives: To explore pedagogical goals and concerns in National Education Policy (NEP 2020), Ministry of Human Resource Development, Government of India. The current review tries to find some ways and methods to make learning process enjoyable and meaningful as desired by NEP 2020. The roles of concept mapping in achieving the pedagogical goals of NEP 2020, also objectify this paper. Method/Analysis: In pursuing of the objectives, NEP 2020 and a set of articles related to the topic were explored. This study provides critical analysis and review on the role of concept mapping in achieving the pedagogical goals of NEP 2020. The paper deals with the common concerns of NEP2020 and Concept Mapping. Findings: The outcome of the review is that Concept mapping can offer an effective tool in education for both, teaching and learning process by supporting an active and meaningful learning. Concept maps provide a unique graphical view of how students organize, connect, and synthesize information. Concept maps give students an opportunity to think about the connections between the concepts being learnt and reflect on their understanding of the concept which develops critical thinking of the learners. Further, it provides platform for collaboration, discussion; arriving at shared understandings among members of groups. Concept map can be used to replace rote learning with meaningful and enjoyable learning. Novelty: NEP 2020 has been explored and taken into consideration keenly to find its pedagogical goals. The role of concept mapping in achieving pedagogical goals of NEP 2020 has been highlighted in the present paper. Thus, the paper explores how concept mapping can be an effective tool in contributing to a great extent to meet the pedagogical goals of NEP 2020.

Keywords: National Education Policy 2020; Pedagogy; Critical Thinking; Concept Mapping

\section{Introduction}

"Education is fundamental for achieving full human potential, developing an equitable $\&$ just society, thus; promoting national development. Providing universal access to 
quality education is the key to India's continued ascent, and leadership on the global stage in terms of economic growth, social justice and equality, scientific advancement, national integration and cultural preservation. Universal high-quality education is the best way forward for developing and maximizing our country's rich talents and resources for the good of the individual, the society, the country and the world." ${ }^{(1)}$ In the introduction section of the National Education Policy 2020, its vision and objectives of education are clearly stated which reflects the importance of concept mapping and developing critical thinking in the learners today. Further the document says, "Pedagogy must evolve to make education more experiential, holistic, integrated, inquiry-driven, discovery-oriented, learner-centered, discussion-based, flexible, and, of course, enjoyable" (NEP2020) ${ }^{(1)}$. Here, it suggests and proposes as how education should be imparted. The present paper enquires into various researches and reallife experiences pertaining to concept maps and collaborative concept mapping. The paper tries to justify concept maps and collaborative concept mapping as a tool to contribute to meet the educational mission and desires of NEP 2020.

\section{Pedagogical Goals in NEP 2020}

Under Heading 4, titled- "Curriculum and Pedagogy in Schools: Learning Should be Holistic, Integrated, Enjoyable, and Engaging" the Policy document in sub points- 4.2, 4.4, and 4.5, directs some certain pedagogical concerns which can be placed in the following heads :

1. Discussion of the more abstract concepts in each subject.

2. Explorations of relations among different subjects.

3. Experiential learning within each subject.

4. Learning how to learn.

5. Education away from the culture of rote learning as is largely present today.

6. Development of critical thinking.

7. The content will focus on key concepts.

8. Discussion-based learning.

9. Input of collaborative activities for deeper learning.

In the review article on NEP 2020, Panditrao and Panditrao ${ }^{(2)}$ found that there is an emphasis on conceptual understanding, creativity and critical thinking to encourage logical decision-making and innovation rather than rote learning and learning for examinations.

\section{Prevalence of the Culture of Rote Learning: A key concern of NEP 2020}

The National Education Policy 2020 states clearly the prevalent culture of rote learning present in education system till today. This one fact hinders in achieving all other pedagogical goals leading to problems faced by learners in their holistic development. If there is prevalence of rote learning, there cannot be effective experiential learning, nor there can be a scope of critical thinking among the students. The researcher also enquired and found the same. Following is the elaboration of how the researcher came to know of the fact of rote learning through personal experiences and scientific investigation. Numerous literature reviews advocate meaningful learning for quality education and opposed Rote learning. A survey conducted by the Hindu reveals that rote learning is prevalent in top schools too. ${ }^{(3)}$ According to Catherin 2018, Rote learning today is a staple in schools across the country. Not just teachers but even parents, find themselves saying "mug up and you'll pass" to help their children make it through their exams. ${ }^{(4)}$ There are various other evidences that indicate towards rote learning. In many schools, answers are ticked by teacher, copied and to be learned as it is by students. Such practices encourage rote learning and discourage self-expression as they have to copy from book or note down the prescribed answers. Learning answers "as it is" without any understanding provides less scope of creativity and self-expression. The researcher also asked the following set of two questions from 60 students including some college students too. The questions asked are as follows:

1. The length of a computer keyboard is around:
(a) $\frac{1}{2}$ meter
(b) $\frac{1}{4}$ meter
(c) 1 Meter
(d) 1.5 Meter 
2. Which of the following on the Earth cannot get vertical rays from the sun?
(a) $0^{\circ}$ latitude
(b) $15^{\circ} \mathrm{N}$ latitude
(c) $23 \frac{1}{2}^{\circ} \mathrm{S}$ latitude
(d) $25^{\circ} \mathrm{N}$ latitude

It was surprisingly observed that only 27 students out of 60 answered the first question correctly while second question was answered correctly only by 12 students. In other words, 33 students in first question and 48 students in second question failed to give correct answers. These two questions must have been answered easily by any student who passed class VI. National Curriculum Framework (NCF 2005) Developed by the National Council for Educational Research and Training, the NCF strongly advocated a move away from rote learning and toward more child centered practices. ${ }^{(5)}$

It can be concluded from the above observation that rote learning is not a practice adopted by one or two schools; it is rather a trend, a problem prevailing in Indian education system.

\section{Concept Mapping}

A concept map (CM) is simply a kind of diagram that displays the relationships between concepts. The idea was originally developed by Joseph Novak in the 1970s. It is a schematic device for representing a set of concepts meaning embedded in a framework of propositions. ${ }^{(6)}$ These are graphical tools for organizing and representing knowledge in a logical sequence. A Concept Map's structure seems to be a mental presentation of knowledge, that Collins and Quillian (1972) ${ }^{(7)}$ labelled "Semantic Memory". CM may help a learner to memorize a specific content in a meaningful way and also to promote, more casually, relevant reading comprehension skills. They are mainly made up of the following constituents:

\section{Concept}

A concept can be defined as a perceived regularity (or pattern) in events or objects, or records of events or objects, designated by label. Concepts are usually enclosed in circles or boxes of some type.

\section{Linking words}

Words on the line, referred to as linking words or linking phrases, specifying the relationship between the two concepts.

\section{Proposition}

According to Oxford advanced learner's dictionary of current English; ${ }^{(8)}$ " "Proposition is a statement that expresses an opinion." Propositions are statements about some object or event in the universe, either naturally occurring or constructed. Propositions contain two or more concepts connected using linking words or phrases to form a meaningful statement. These connected terms can be read as a sentence, such as "India has democracy." These sentences-two terms linked by an arrow and phrase-are called propositions. ${ }^{(9)}$

\section{Collaborative Concept mapping}

Collaborative concept mapping engages two or more students in coordinated and sustained efforts in the creation of one or more concept maps in order to learn and construct knowledge. It is a potentially powerful instructional strategy which fosters meaningful learning and group knowledge construction which further helps the building of common ground among learners. This "inter-learner interaction" can foster learning through student collaboration and knowledge sharing. Learnerlearner interaction can significantly encourage the development of student expertise in different subject areas and promote community building.

According to some researchers collaborative learning is the task-focused interaction among students that enhances learning by creating conflicts, by exposing students to higher levels of thinking, and engaging them in higher level interaction. ${ }^{(10)}$ Collaborative concept mapping provides for students the ability to externalize internal thoughts, while collaborating is a venue for exploring and discussing such externalizations. It has been suggested by Daley, Durning and Torre ${ }^{(11)}$ in their study that the teacher can ask different groups of students to create a map and then ask each group to share their map with another group of students. The teacher can then evaluate possible changes in maps made by one group compared 
the other group's map. Group map sharing allows the individual students and the group as a whole to view the work of other students, discover different approaches and obtain input while constantly learning from each other.

\section{Role of concept mapping in achieving pedagogical goals of NEP 2020}

There are certain pedagogical concerns in NEP 2020 such as-Discussion upon abstract concepts of each subject, experiential learning within each subject, education away from the culture of rote learning, discussion-based learning, input of collaborative activities for deeper learning etc. Concept mapping as a tool can help to a great extent in achieving such goals.

Concept map as a pedagogical and assessment tool in Education may offer an effective tool for teaching-learning process in an effective manner. Concept maps provide a unique graphical view of how students organize, connect, and synthesize information. As a result, concept mapping proves to be beneficial for both, students and teachers. Concept maps give students an opportunity to think about the connections between the concepts being learnt, organize their thoughts and visualize the relationships between key concepts in a systematic way, and are able to reflect on their understanding. The results of the study done by Sharma, and Singh; ${ }^{(12)}$ evidently proved that achievement in Economics of the group exposed to collaborative concept mapping strategy was significantly more than compared to group taught by conventional method. The study done by Tyagi and Pandey ${ }^{(13)}$ indicated a significant impact of Collaborative Concept Mapping on students' understanding of concepts in social science.

To sum up, concept maps allow students to think deeply about their learning by helping them to better understand and organize what they learn, to store and retrieve information more efficiently. Students also articulate and challenge their thoughts when they discuss their maps with each other. Concept maps are also valuable tools for teachers because they provide information about students' understanding. Teachers can examine how well a student understands subject by observing the sophistication of their concept map. Teachers can quickly see gaps in learning and modify lesson plans based on the information from students' concept maps.

\section{Effectiveness of Concept mapping}

Sharma \& Elbow ${ }^{(14)}$ observe that Students are frequently conditioned in their approach to learning by experiences in teachercentered, textbook-driven classrooms. This situation is a disturbing case for contemporary educators, and for this reason they would rather choose the latest models and methods which are more effective in directing students to thinking. Ghazivakili et al. ${ }^{(15)}$ investigated that Critical thinking occurs when students engage in analyzing, evaluating, interpreting, or synthesizing information and applying creative thought to form an argument, solve a problem, or reach a conclusion. Several studies show that the use of concept mapping in teaching learning process lays positive effect. Eachempati et al. ${ }^{(16)}$ found that when concept mapping is used as teaching tool; it has positive effect on the students and helps to outperform the students adopting traditional approach. In his study Ahuja ${ }^{(17)}$ also concluded that concept mapping aims at the teaching and learning of concepts at "understanding level" in a meaningful way. It was also supported by Sivaraman ${ }^{(18)}$ who found that concept mapping is an effective teaching-learning method in Biochemistry than the regular lecture classes.

Since their development, concept maps have been widely used for many purposes and in numerous different contexts. Concept maps have also been useful for:

1. Providing a summary of a person's existing knowledge

2. Identifying misconceptions

3. Revealing gaps in understanding

4. Promoting reflective thinking

5. Designing curricula and instructional materials

6. Assessing students' learning

7. Evaluating program effectiveness

8. Facilitating communication and arriving at shared understanding among members of groups

\section{Relationship between NEP 2020 and Concept Mapping}

The figure presents common concerns of NEP2020 and Concept mapping. The upper oval represents NEP 2020 partially; while the lower oval represents concept mapping with its rich contribution in terms of: collaborative learning, enjoyable learning, clarity of concepts, meaningful learning and critical thinking. The Intersecting area which is common to both the ovals; represents the relationship between NEP2020 and concept mapping. 


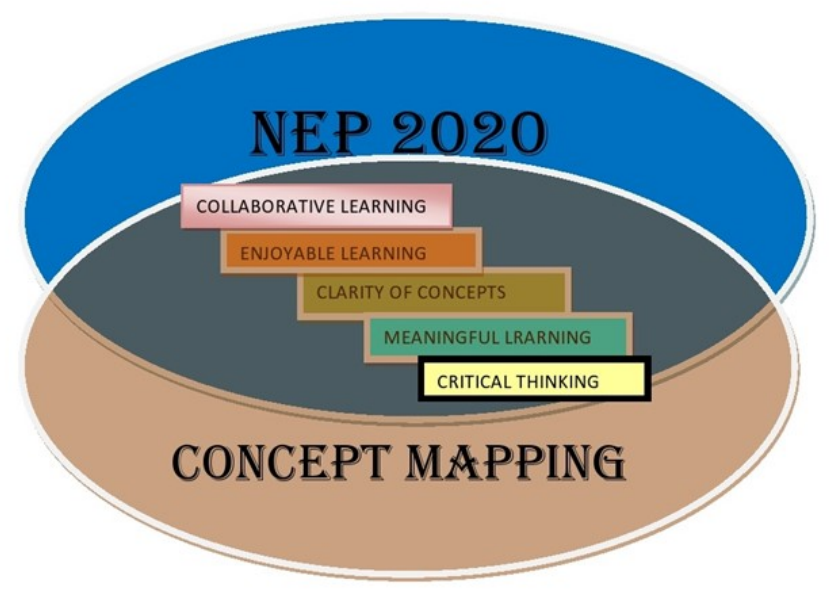

Fig 1. NEP2020 and Concept mapping

\section{Recommendations}

Based on the findings of the study, the following recommendations are made:

1. Pre-service teachers and in-service teachers should be given training as how to use concept mapping and collaborative concept mapping effectively in the teaching learning process.

2. All teachers should use concept mapping or collaborative concept mapping in some way or the other because they have been found an effective tool for meaningful learning.

3. Concept mapping must be given space in all the text books wherever possible. Such exposure through text books will lead students towards key concepts of the topics and better understanding.

4. Collaborative concept mapping should be used for the development of discussion-based learning.

5. Information and communication technology (ICT) should be used for online concept mapping and collaborative concept mapping.

\section{Conclusion}

National Education Policy 2020 observes the culture of rote learning largely used till today. The policy, NEP2020, therefore expresses certain concerns and goals pertaining to pedagogy. On the basis of this review, it can be said that Concept mapping as a strategy can contribute to a great extent to meet the educational mission and desires of NEP 2020. Thus, Concept mapping may offer an effective tool in education for both teaching and learning by supporting an active and meaningful learning.

\section{References}

1) National Education Policy 2020. 2020. Available from: https://www.education.gov.in/sites/upload_files/mhrd/files/NEP_Final_English_0.pdf.

2) Panditrao MM, Panditrao MM. National Education Policy 2020: What is in it for a student, a parent, a teacher, or us, as a Higher Education Institution/University? Adesh University Journal of Medical Sciences \& Research. 2020;2(2):70-79. Available from: https://dx.doi.org/10.25259/aujmsr_ 32_2020. 
3) Venkataramanan K. Learning by rote prevalent in top schools too . 2016. Available from: https://www.thehindu.com/opinion/op-ed/learning-by-roteprevalent-in-top-schools-too/article2707183.ece.

4) Catherin A. English Rote Learning; An Introspection, New Perspectives in ELT. vol. 18. 2018;p. 13-16. Available from: http://www.languageinindia.com/ april2018/theniseminar2/theniseminar2018volume.pdf.

5) National Council of Educational Research and Training. 2005.

6) Novak JD, Gowin DB, Kahle JB. Learning How to Learn. Cambridge. Cambridge University Press. 1984;p. 7. Available from: https://doi.org/10.1017/ CBO9781139173469.

7) Collins AM, Quillian MR. Experiments on semantic memory and language comprehension. In: Gregg LW, et al., editors. Cognition in learning and memory. John Wiley \& Sons. 1972.

8) Oxford advanced learner's dictionary of current English. Michael Ashby. 2003;p. 1017.

9) Cañas AJ, Novak JD. The Theory Underlying Concept Maps and How to Construct and Use them. 2008.

10) Webb NM. Peer interaction and learning in small groups. International Journal of Educational Research. 1989;13:21-39. doi:10.1016/0883-0355(89)900141.

11) Daley BJ, Durning SJ, Torre DM. Using Concept Maps to Create Meaningful Learning in Medical Education. MedEdPublish. 2016;5(1):19. Available from: https://dx.doi.org/10.15694/mep.2016.000019.

12) Sharma M, Singh G. Effect of collaborative concept mapping strategy on achievement in economics of ix graders. International Education and Research Journal. 2016;2(7):22-25.

13) Tyagi H, Pandey S. The Impact of Collaborative Concept Mapping on Student' Conceptual Understanding in Social Science. International Journal of Innovative Knowledge Concepts. 2019;7(7):145-150.

14) Sharma M, Eelbow GS. Using Internet Primary Sources to Teach Critical Thinking Skills in Geography. Greenwood Publishing Group. 2000.

15) Ghazivakili Z, Nia RN, Panahi F, Karimi M, Gholsorkhi H, Ahmadi Z. The role of critical thinking skills and learning styles of university students in their academic performance. J Adv Med Educ Prof. 2014;2(3):95-102.

16) Eachempati P, Ramnarayan K, K KS, Mayya A. 'Concept Maps for Teaching, Training, Testing and Thinking. 2020;9(1):171. Available from: https: //doi.org/10.15694/mep.2020.000171.1.

17) Ahuja A. Concept mapping as an effective teaching practice in science in education. Techno LEARN. 2013;3(1):27-32. Available from: https: //ndpublisher.in/admin/issues/tlv3n1d.pdf.

18) Sivaraman SK. Concept mapping, an innovative educational tool in learning biochemistry. International Journal of Medical Science and Education. 2020;7(3):1-5. 